九州大学学術情報リポジトリ

Kyushu University Institutional Repository

\title{
Poly(methyl methacrylate) grafted imogolite nanotubes prepared through surface-initiated ARGET ATRP
}

Ma, We i

Graduate School of Engineering, Kyushu University

Otsuka, Hideyuki

Institute for Materials Chemistry and Engineering, Kyushu University I Graduate School of Engineering, Kyushu University

Takahara, Atsushi

Institute for Materials Chemistry and Engineering, Kyushu University | Graduate School of Engineering, Kyushu University

http://hdl. handle. net/2324/25503

出版情報: Chemical Communications. 47 (20)，pp.5813-5815，2011-04-12. Royal Society of Chemistry

バージョン:

権利関係: (C) The Royal Society of Chemistry 2011 


\title{
Poly(methyl methacrylate) grafted imogolite nanotubes prepared through surface-initiated ARGET ATRP
}

\author{
Wei Ma, ${ }^{a}$ Hideyuki Otsuka ${ }^{\text {a,b }}$ and Atsushi Takahara $*^{a, b}$
}

\author{
${ }_{5}$ Received $2^{\text {nd }}$ February 2011, Accepted $24^{\text {th }}$ March 2011 \\ DOI: $10.1039 /$ clcc1066la
}

Poly(methyl methacrylate) grafted imogolite clay nanotubes were fabricated via activators regenerated by electron transfer for atom transfer radical polymerization (ARGET ATRP) by ${ }_{10}$ designing a water soluble amphiphilic ATRP initiator that can adsorb onto imogolite surface in an aqueous solution.

Nanotubular materials are important building blocks for future nanotechnology and have been attracting research interests over the past two decades. Among various nanotubes, an 15 increasing attention has been being paied to clay-based ones, such as halloysite, ${ }^{1}$ since they are friendly with nature and abundant in source. Imogolite is another interesting, but not yet commercialized clay nanotube widely distributed in volcanic ash soils and weathered pumice beds. Imogolite has a 20 single-walled tubular structure with internal and external diameter of about 1 and $2 \mathrm{~nm}$, respectively, and average length of approximately $100 \mathrm{~nm} .^{2-5}$ It has a curved gibbsitelike sheet presenting an $\mathrm{SiOH}$-functionalized interior and an $\mathrm{AlOH}-$ functionalized exterior, thus can be positively charged 25 and dispersed in a low $\mathrm{pH}$ solution. Apart from naturally occurring, imogolite also can be synthesized from inexpensive materials. ${ }^{6}$ In the past few decades, numerous applications of imogolite have been reported, including shape selective catalyst, ${ }^{7}$ gas storage, ${ }^{8}$ fillers for organic/inorganic hybrid 30 materials, ${ }^{9-11}$ and building blocks for self-assembly. ${ }^{12,13}$ With the development of new synthetic protocols in recent years, large quantity production of synthetic imogolite could potentially stimulate new interests in imogolite research and open up possibilities for large-scale applications. ${ }^{14,15}$ One

${ }_{35}$ challenge involving imogolite application is their homogeneous dispersion in hydrophobic materials, which is particularly necessary for achieving their full potential applications, especially in the field of transparent nanocomposites. ${ }^{9}$ Surface modification, which can convert the 40 hydrophilic surface of imogolite to hydrophobic has been carried out by several groups. ${ }^{16-18}$ Very recently, we demonstrated the hydrophobization of imogolite at nanotube level from an aqueous solution. ${ }^{19}$ However, those low molecular weight compounds were not sufficient for ${ }_{45}$ preventing nanotube aggregation.
Since surface grafting of polymers has been developed as a powerful technique for dispersing nanostructures, ${ }^{20-22}$ poly(methyl methacrylate) (PMMA) was grafted to imogolite surface via a grafting through method in our previous work. ${ }^{10}$ ${ }_{50}$ Nevertheless, the resulting grafted imogolite cannot be homogeneously dispersed as its dispersion looked cloudy. Moreover, the grafting through method always leads to a large amount of unbound polymers, which need extra process to remove. In this communication, obstacles mentioned above s5 were broken through by employing a surface-initiated polymerization of methyl methacrylate (MMA) from imogolite surface. Atom transfer radical polymerization (ATRP) technique called activators regenerated by electron transfer for atom transfer radical polymerization (ARGET ${ }_{60}$ ATRP) $)^{23,24}$ was employed in this study, because it can be carried out without strict deoxygenation and only need ppm level of catalyst. Scheme 1 presents the preparation procedure of PMMA grafted imogolite nanotube.

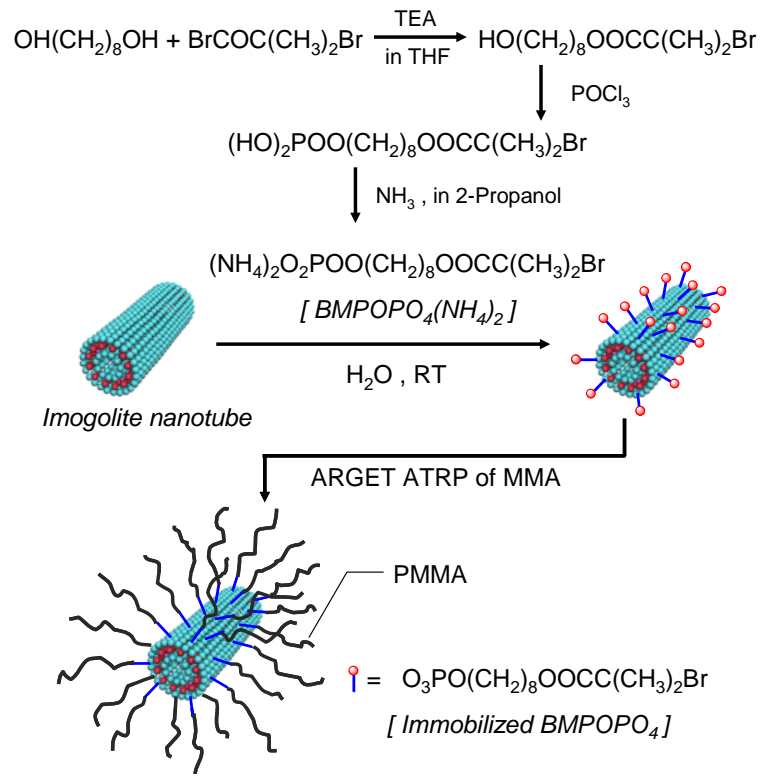

Scheme1. Schematic representation for the preparation of PMMA 65 grafted imogolite nanotube. 
To realize polymerization of MMA from the surface of imogolite nanotubes, a water soluble ATRP initiator was developed. As shown in Scheme 1, the designed ATRP initiator, ammonium salt of 8-(2-bromo-25 methylpropanoyloxy) octyl phosphate $\left[\mathrm{BMPOPO}_{4}\left(\mathrm{NH}_{4}\right)_{2}\right]$, has both a 2-bromoisobutyrate group as ATRP initiator moiety and a phosphate group which can be expected to interact with imogolite surface. ${ }^{17,19}$ Immobilization of the initiator to imogolite surface was conducted as follow. 10 Imogolite solution was mixed with aqueous solution of $\mathrm{BMPOPO}_{4}\left(\mathrm{NH}_{4}\right)_{2}$ and stirred at room temperature for 48 hours. The product was isolated by filteration and washed with $\mathrm{THF} / \mathrm{H}_{2} \mathrm{O}$ (volume ratio of $1: 1$ ) by several dispersioncentrifugation cycles to give a white product of 8-(2-bromo-215 methylpropanoyloxy) octyl phosphate modified imogolite $\left(\mathrm{BMPOPO}_{4}\right.$-imogolite). The adsorption of $\mathrm{BMPOPO}_{4}$ onto imogolite surface was confirmed by FT-IR and XPS measurements. The amount of adsorbed $\mathrm{BMPOPO}_{4}$ was estimated to be $49 \mathrm{wt} \%$ by thermogravimetric analysis (TGA).

20 The subsequent ARGET ATRP was carried out by using ascorbic acid (AA) as the reducing agent and anisole as solvent. ${ }^{25}$ Ascorbic acid is insoluble in anisole, hence, the reduction of $\mathrm{Cu}$ (II) complex takes place at the surface of solid ascorbic acid. The slow reaction rate of this heterogeneous 25 redox process is beneficial for building up a necessary equilibrium between the activator $(\mathrm{Cu}(\mathrm{I})$ complex) and deactivator $\left(\mathrm{Cu}(\mathrm{II})\right.$ complex). In a typical recipe, $\mathrm{CuBr}_{2}$ and $N, N, N^{\prime}, N^{\prime \prime}, N^{\prime \prime}$-pentamethyldiethylenetriamine (PMDETA) were dissolved in anisole. After the formation of $\mathrm{Cu}$ (II) 30 complex, initiator, ascorbic acid and MMA were added. The resulting mixture was sealed with a rubber septum and deoxygenated by argon bubbling for $5 \mathrm{~min}$ at room temperature and subsequently placed in an oil bath thermostated at $40{ }^{\circ} \mathrm{C}$. The polymerization was stopped by 35 opening the flask and exposing the catalyst to air. Polymeric products were isolated by precipitation from methanol. In order to get a relatively low molecular weight distribution for the grafted polymers, surface-initiated ARGET ATRP was carried out by employing a short reaction time. Moreover, no 40 sacrificial initiator was added to the polymerization mixture for mitigating the high monomer-to-initiator ratio and eventually getting a better control over the polymerization, ${ }^{26}$ because this is beneficial for avoiding the difficulty of removing free polymer from grafted products. PMMA was 45 cleaved from imogolite surface by $\mathrm{HF} / \mathrm{HCl}$ for $\mathrm{GPC}$ measurements. GPC data showed that grafted PMMA with molecular weight of $M_{n}=26600$ and 32700, and the corresponding molecular weight distribution of $M_{w} / M_{n}=1.22$ and 1.33 were obtained after the polymerization time of 50 50 and $90 \mathrm{~min}$, respectively. Hence, grafted PMMA with controllable molecular weights can be achieved by controlling reaction time.

Bare imogolite cannot be dispersed in any organic solvent. After modified with $\mathrm{BMPOPO}_{4}$, the resulting modified

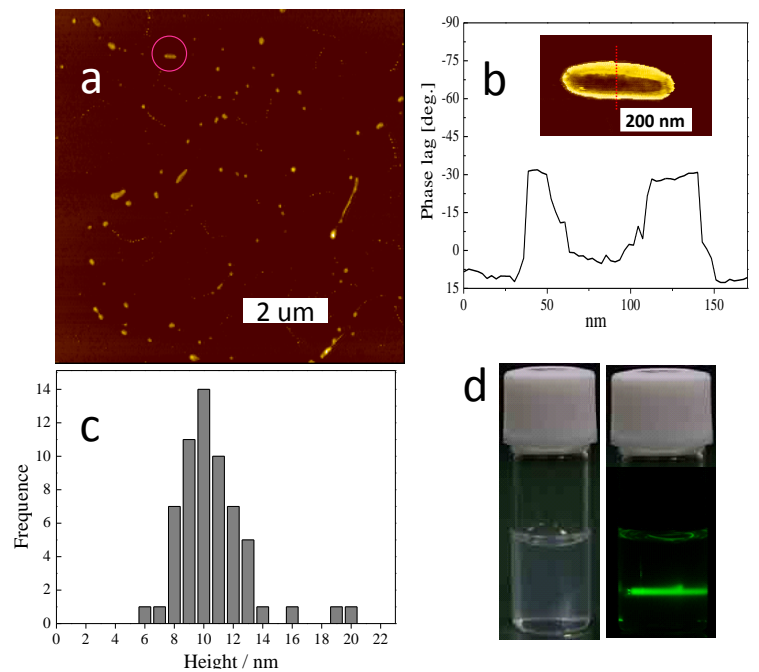

Figure 1. (a) A SFM height image of PMMA grafted imogolite $\left(M_{n}=\right.$ $32700, M_{w} / M_{n}=1.33$ ). (b) A phase image (insert) and cross-sectional analysis of a PMMA-g-imogolite marked with a circle in (a). (c) Height distribution of the above sample as estimated by SFM. (d) Photographs of THF dispersion of the same sample with a concentration of $10 \mathrm{mg} / \mathrm{mL}$ (the one on the right shows scattering of a green light beam by the dispersion due to the Tyndall effect).

55 imogolite can disperse in various solvents. Unfortunately, their dispersions are neither homogenous nor stable. However, when PMMA was grafted to the surface of imogolite nanotubes, PMMA-g-imogolite showed good dispersibility in organic solvents, such as THF, chloroform, and toluene. As ${ }_{60}$ shown in Figure 1 (d) the homogenous dispersion of PMMAg-imogolite in THF with a concentration of $10 \mathrm{mg} / \mathrm{mL}$ was stable for more than two months.

Morphology of PMMA grafted imogolite nanotubes was observed with scanning force microscopy (SFM) in a dynamic 65 force microscopy (DFM) mode using a sharp diamond-like carbon (DLC) tip with curvature radius of $1 \mathrm{~nm}$. Figure 1a shows a height image of one sample with $M_{n}=32700$ and $M_{n} / M_{w}=1.33$. Discrete nanostructures were randomly distributed on the mica surface and no aggregation was 70 observed, indicating excellent dispersibility of PMMA grafted imogolite. High resolution phase image and the corresponding cross-section analysis in Figure $1 \mathrm{~b}$ indicates that PMMA grafted imogolite render a hard middle part and soft edge. This further confirms the core-shell structure of PMMA- $g$ 75 imogolite. Individual bare imogolite has a height of ca. $3.0 \mathrm{~nm}$, as shown in Figure S1. For PMMA grafted imogolite, however, the height is not as uniform as that of bare imogolite. Figure 1c shows the height distribution of the above PMMA$g$-imogolite analyzed from 60 SFM images. The average 80 height value was obtained to be $10.6 \pm 2.5 \mathrm{~nm}$, although there are still some images having heights more than $15 \mathrm{~nm}$. If we consider the sample with the smallest height value $(6 \mathrm{~nm})$ contains an individual imogolite nanotube as the core, the ones with larger height values are expected to have nanotube 85 bundles as their rigid cores. Imogolite we used was purified 
by gelation with aqueous solution of sodium chloride. ${ }^{9}$ In the gelation process, imogolite dispersion loses stability and likely forms bundles. Further evidence on the bundle structures was provided by wide angle X-ray diffraction

5 (WAXD) measurements. WAXD analysis indicates that the small sized bundles inside PMMA-g-imogolite are highly ordered. The detailed information on WAXD analysis can be found in the + ESI.

In summary the authors successfully prepared the 10 poly(methyl methacrylate) grafted imogolite clay nanotubes by surface-initiated ARGET ATRP of MMA. ATRP initiator was immobilized onto imogolite surface by developing a water soluble amphiphilic surface modifier $\mathrm{BMPOPO}_{4}\left(\mathrm{NH}_{4}\right)_{2}$ with both an ATRP initiator moiety and a phosphate group. ${ }_{15}$ Small sized imogolite bundles with high regularity are confirmed to exist as the cores of PMMA-g-imogolite. Since the poly(methyl methacrylate) grafted imogolite nanotubes disperse stably in organic solvents such as THF, chloroform, and toluene, they can be used as nanofillers for polymer 20 matrix. The applications of this polymer grafted imogolite in various organic/inorganic hybrid materials are currently under investigation.

The authors acknowledge the financial support of a Grantin-Aid for Scientific Research (A) (No.19205031) from Japan ${ }_{25}$ Society for the Promotion of Science. The present work is also supported by a Grant-in-Aid for the Global COE Program, "Science for Future Molecular Systems" from the Ministry of Education, Culture, Science, Sports and Technology of Japan. The synchrotron radiation experiments were performed at ${ }_{30}$ BL02B2 in SPring-8 with the approval of the JASRI (Proposal No. 2010A1454).

\section{Notes and references}

${ }^{a}$ Graduate School of Engineering, Kyushu University, Fukuoka 819-0395, Japan.

$35{ }^{b}$ Institute for Materials Chemistry and Engineering, Kyushu University, Fukuoka 819-0395, Japan.

Fax: 81-92-802-2518; Tel: 81-92-802-2517; E-mail:

takahara@cstf.kyushu-u.ac.jp.

$\dagger$ Electronic Supplementary Information (ESI) available: Experimental
40 details, synthetic characterization, SFM image of bare imogolite, FT-IR spectra, TGA curves, WAXD profiles and discussion. See DOI: $10.1039 / \mathrm{b} 000000 \mathrm{x} /$

1 N. G. Veerabadran, D. Mongayt, V. Torchilin, R. R. Price and Y. M. Lvov, Macromol. Rapid Commun., 2009, 30, 99.

452 K. Wada and N. Yoshinaga, Am. Mineral., 1969, 54, 50.

3 P. D. G. Cradwick, V. C. Farmer, J. D. Russell, C. R. Masson, K. Wada and N. Yoshinaga, Nat. Phys. Sci., 1972, 240, 187.

4 S. Mukherjee, V. M. Bartlow and S. Nair, Chem. Mater., 2005, 17, 4900.

505 H. Yang, C. Wang and Z. Su, Chem. Mater., 2008, 20, 4484.

6 V. C. Farmer, A. R. Fraser and J. M. Tait, J. Chem. Soc., Chem. Commun., 1977, 462.

7 S. Imamura, T. Kokubu, T. Yamashita, Y. Okamoto, K. Kajiwara and H. Kanai, J. Catal., 1996, 160, 137.

558 F. Ohashi, S. Tomura, K. Akaku, S. Hayashi and S.-I. Wada, J. Mater. Sci., 2004, 39, 1799.

9 K. Yamamoto, H. Otsuka, S.-I. Wada, D. Sohn and A. Takahara, Soft Matter, 2005, 1, 372.

10 K. Yamamoto, H. Otsuka, S.-I. Wada, D. Sohn and A. Takahara, Polymer, 2005, 46, 12386.

11 N. Inoue, H. Otsuka, S.-I. Wada and A. Takahara, Chem. Lett., 2006, 35, 194.

12 H. Yang, Y. Chen and Z. Su, Chem. Mater., 2007, 19, 3087.

13 Y. Kuroda and K. Kuroda, Sci. Technol. Adv. Mater., 2008, 9, $65 \quad 025018$

14 C. Levard, J. Rose, A. Masion, E. Doelsch, D. Borschneck, L. Olivi, C. Dominici, O. Grauby, J. C. Woicik and J.-Y. Bottero, J. Am. Chem. Soc., 2008, 130, 5862.

15 C. Levard, A. Masion, J. Rose, E. Doelsch, D. Borschneck, C. Dominici, F. Ziarelli and J.-Y. Bottero, J. Am. Chem. Soc., 2009, 131, 17080

16 L. M. Johnson and T. J. Pinnavaia, Langmuir, 1990, 6, 307.

17 K. Yamamoto, H. Otsuka, S.-I. Wada and A. Takahara, Chem. Lett., 2001, 30, 1162.

7518 D. L. Guerra, A. C. Batista, R. R. Viana and C. Airoldi, J. Hazard. Mater., 2010, 183, 81

19 W. Ma, J. Kim, H. Otsuka and A. Takahara, Chem. Lett., 2011, 40, 159.

20 C. Perruchot, M. A. Khan, A. Kamitsi, S. P. Armes, T. von Werne and T. E. Patten, Langmuir, 2001, 17, 4479.

21 C. R. Vestal and Z. J. Zhang, J. Am. Chem. Soc., 2002, 124, 14312.

22 R. Matsuno, K. Yamamoto, H. Otsuka and A. Takahara, Chem. Mater., 2003, 15, 3.

23 W. Jakubowski, K. Min and K. Matyjaszewski, Macromolecules, 2006, 39, 39.

24 K. Matyjaszewski, W. Jakubowski, K. Min, W. Tang, J. Huang, W. A. Braunecker and N. V. Tsarevsky, Proc. Natl. Acad. Sci., 2006, 103, 15309 .

25 K. Min, H. Gao and K. Matyjaszewski, Macromolecules, 2007, 40, 1789.

26 T. von Werne and T. E. Patten, J. Am. Chem. Soc., 2001, 123, 7497. 